\title{
Stability Indicating Methods for the Determination of Norfloxacin in Mixture with Tinidazole
}

\author{
Mohammad Abdul-Azim Mohammad, ${ }^{a}$ Nagwan Hamdy Zawilla, ${ }^{b}$ Fawzy Mohammad El-Anwar, ${ }^{b}$ \\ and Samir Mohammad El-Moghazy Aly*,a \\ ${ }^{a}$ Pharmaceutical Chemistry Department, Faculty of Pharmacy, Cairo University; Kasr El-Aini Street, Cairo 11562, Egypt: \\ and ${ }^{b}$ National Organization for Drug Control and Research; Cairo, Egypt. \\ Received April 10, 2006; accepted September 4, 2006
}

Three stability indicating assay methods are developed for the determination of norfloxacin (Nor) in the presence of its decarboxylated degradation product and in mixture with tinidazole (Tnd). The proposed methods are reversed phase ion pair liquid chromatography (LC), thin layer densitometry (TLC) and second derivative ratio spectra zero crossing spectrophotometry $\left({ }^{2} \mathrm{DD}\right)$. Chromatographic separation was achieved on $\mu$-Bondapack C18 column $5 \mu \mathrm{m}(300 \mathrm{~mm} \times 3.9 \mathrm{~mm}$, I.D.) and precoated silica gel TLC stationary phases for LC and TLC methods, respectively. Mobile phases consisting of phosphate buffer $\mathrm{pH} 3.2$ : methanol $(3: 1$, v/v) containing $0.005 \mathrm{M}$ pentane sulfonic acid sodium salt and isopropanol:butanol:concentrated ammonia: water $(25: 50$ : $5: 25, v / v / v / v)$ were used for resolution of Nor and Tnd by both techniques, respectively. Detection was carried at $280 \mathrm{~nm}$. In the ratio spectra method, detection of Nor was carried at $282 \mathrm{~nm}$. Linearity, accuracy and precision were found to be acceptable over concentration ranges of $20-225 \mu \mathrm{g} / \mathrm{ml}, 0.8-4 \mu \mathrm{g} / \mathrm{spot}$ and $1-7 \mu \mathrm{g} / \mathrm{ml}$ for Nor by LC, TLC and ${ }^{2}$ DD methods and over concentration ranges of $37.5-375 \mu \mathrm{g} / \mathrm{ml}$ and $4.8-20 \mu \mathrm{g} / \mathrm{spot}$ for Tnd by LC and TLC methods respectively. The suggested methods were successfully applied for the determination of both drugs in bulk powder, laboratory prepared mixtures and in commercial samples. Statistical comparison between the results obtained by the proposed and the reference methods was carried out using Student $t$-test, $F$ ratio and one way ANOVA.

Key words norfloxacin; tinidazole; liquid chromatography; TLC; densitometry; second derivative of ratio spectra

Norfloxacin (Nor), (1-ethyl-6-fluoro-1,4-dihydro-4-oxo-7 (1-piperazinyl)-3-quinoline carboxylic acid is a synthetic antibacterial drug. ${ }^{1,2)}$ Methods were reported for its determination as titrimetric, ${ }^{3)} \mathrm{LC},{ }^{4-10)} \mathrm{LC}-\mathrm{MS},{ }^{11-13)}$ spectrometric, ${ }^{14-16)}$ spectrofluorimetric ${ }^{17-20)}$ and electrochemical. ${ }^{21)}$ Tinidazole (Tnd), 1-[2-(ethyl sulfonyl)ethyl]-2-methyl-5-nitro-1 $H$-imidazole is an antiprotozoal, antiamaebic and antibacterial drug. ${ }^{22,23)}$ Methods were reported for its determination such as titrimetric, ${ }^{24)} \mathrm{LC},{ }^{25,26)} \mathrm{LC}^{-\mathrm{MS}^{27)}}$ and spectrometric. ${ }^{28,29)}$

The combination of Nor and Tnd is widely used in the treatment of gastrointestinal infections. Both drugs were simultaneously determined by LC, ${ }^{30,31)}$ TLC-densitometric, ${ }^{32,33)}$ and spectrometric methods. ${ }^{34-38)}$

The objective of this work is to develop selective, accurate and sensitive assay procedures for simultaneous determination of Nor and Tnd in presence of the closely related norfloxacin 3-decarboxylated degradation product, which has a particular importance because of its identification as a precipitate in Nor injections ${ }^{39)}$ and as an impurity in Nor powder. $^{40)}$

The suggested chromatographic methods have the advantages of being both stability indicating for Nor and capable of simultaneous determination of Nor and Tnd. These advantages are not found in combination ${ }^{30-38)}$ in the afore mentioned methods. In addition, the chromatographic conditions used in these methods are capable to detect Nor decarboxylated degradation product. On the other hand, detection of photodegradation products of Nor could not be afforded in the present work and it was well studied in previous publications. ${ }^{4,5)}$

The proposed second derivative ratio spectrometric method has the advantage of high sensitivity and ability of determining Nor selectively in Nor-Tnd admixture at the zero crossing with its decarboxylated degradate. This advantage could not be afforded by the application of the reported first derivative of the ratio spectra method. ${ }^{38)}$

\section{Experimental}

Materials Nor and Tnd standards of purity $101.08 \pm 0.85(\mathrm{w} / \mathrm{w})$ and $100.57 \pm 0.87(\mathrm{w} / \mathrm{w})$ respectively, according to European Pharmacopoeia 2005 methods, were kindly supplied by Pharaonia Pharmaceuticals (for Wockhardt, Egypt). Conaz ${ }^{\mathbb{R}}$ tablets of batches 16929 and 16932 labeled to contain $400 \mathrm{mg}$ Nor and $600 \mathrm{mg}$ Tnd/tablet were from Pharaonia Pharmaceuticals (for Wockhardt, Egypt).

Apparatus and Reagents A Shimadzu Ultraviolet/Visible spectrophotometer 1601-pc (Tokyo, Japan) with matched $1 \mathrm{~cm}$ quartz cells and connected to IBM compatible computer was used. Shimadzu-Dual wavelength lamp flying CS-9301 densitometer and ultraviolet short wavelength lamp $(254 \mathrm{~nm})$ were used. HPTLC plates were silica gel/TLC cards with fluorescent indicator $(254 \mathrm{~nm})$; layer thickness $0.2 \mathrm{~mm} ; 20 \times 20 \mathrm{~cm}$ aluminum cards (Fluka). HPLC instrument was Hewlett Packard series 1100 equipped with a quaternary pump, diode array detector and a manual injector $20 \mu$ loop (Minnesota, U.S.A.). Detection was carried at $280 \mathrm{~nm}$ and flow rate was $1 \mathrm{ml} / \mathrm{min}$. Column used was $\mu$-Bondapack C18, $5 \mu \mathrm{m}(300 \times 3.9 \mathrm{~mm}$ I.D. $)$ was from Waters (Milford, U.S.A.). Ultrasonic was J.P. Selecta, s-a, CD 300513, Spain. Methanol and acetonitrile (HPLC and Analytical grades) were from Lab scan Analytical Sciences (New Jersey, U.S.A.). Buffer used in mobile phase for LC method was $0.1 \mathrm{M}$ sodium dihydrogen phosphate (Merck, Darmstadt, Germany) containing $0.005 \mathrm{~m}$ pentane sulfonic acid sodium salt and adjusted to $\mathrm{pH} 3.2$ with phosphoric acid. Isopropanol and $n$ butanol were obtained from Lab scan analytical sciences (New Jersey, U.S.A.), pentane sulphonic acid was obtained from Acros organics (Geel, Belgium), phosphoric acid and concentrated ammonia were obtained from Riedel de-Haen (St. Louis, Missouri, U.S.A.)

Preparation of Decarboxylated Nor Decarboxylated Nor was prepared according to the method reported by S. Z. El-Khateeb et al. ${ }^{15)}$ where the decarboxylated Nor was separated and collected from preparative TLC glass plates using the mobile phase applied in the TLC-densitometric method. The scratched degradant was dissolved in methanol and filtered. The filtrate was evaporated to dryness and the residue was collected.

Stock Solutions Four stock solutions were prepared: Stock solution 1: $50 \mathrm{mg}$ Nor was transferred into a 50-ml volumetric flask, dissolved in $2 \mathrm{ml}$ 
$1 \mathrm{~mol} / 1$ sodium hydroxide, $30 \mathrm{ml}$ methanol was then added followed by $2 \mathrm{ml}$ acetonitrile. The final volume was completed with methanol to obtain a solution of $1 \mathrm{mg} / \mathrm{ml}$ Nor.

Stock solution 2: $2 \mathrm{mg} / \mathrm{ml}$ Tnd (prepared as mentioned in stock solution 1 using $100 \mathrm{mg}$ Tnd).

Stock solution 3: $1 \mathrm{mg} / \mathrm{ml}$ decarboxylated Nor (prepared as mentioned under stock solution 1 using $50 \mathrm{mg}$ decarboxylated Nor).

Stock solution 4: $1 \mathrm{mg} / \mathrm{ml}$ and $1.5 \mathrm{mg} / \mathrm{ml}$ of Nor and Tnd respectively (prepared as under stock solution 1 using $50 \mathrm{mg}$ and $75 \mathrm{mg}$ of Nor and Tnd, respectively).

Preparation of Test Solution 20 Conaz $^{\circledR}$ tablets were accurately weighed and ground. A quantity of the thoroughly mixed powder equivalent to $50 \mathrm{mg}$ Nor and $75 \mathrm{mg}$ Tnd was transferred into a $50-\mathrm{ml}$ volumetric flask dissolved in $2 \mathrm{ml} 1 \mathrm{~mol} / 1$ sodium hydroxide, $30 \mathrm{ml}$ methanol was added followed by $2 \mathrm{ml}$ acetonitrile. The solution was sonicated for $30 \mathrm{~min}$; the volume was completed with methanol and then filtered.

Procedures. LC Method Chromatographic Conditions: The mobile phase was flowing at constant rate of $1 \mathrm{ml} / \mathrm{min}$ for $20 \mathrm{~min}$. A $\mu$-Bondapack C18 column $(5 \mu \mathrm{m}, 300 \mathrm{~mm} \times 3.9 \mathrm{~mm})$ was used as stationary phase. Detection was carried out using a UV detector at $280 \mathrm{~nm}$.

Construction of Calibration Curves for Nor and Tnd: Accurately measured aliquots equivalent to $0.2-2.25 \mathrm{mg}$ Nor and $0.375-3.75 \mathrm{mg}$ Tnd from stock solutions 1 and 2 respectively were transferred into two separate series of $10-\mathrm{ml}$ volumetric flasks. The volume was completed with methanol. Twenty microliters of each solution was separately injected into the chromatograph. A calibration curve for each drug was obtained by plotting mean area under the peak (AUP) against drug concentration.

Assay of Laboratory Prepared Mixtures and Conaz ${ }^{\mathbb{B}}$ Tablets: The procedure as under 'Chromatographic Conditions' was carried by mixing aliquots from stock solution 4 equivalent to $0.275-1.75 \mathrm{mg}$ Nor and 0.4125 $2.625 \mathrm{mg}$ Tnd and aliquots of stock solution 3 (decarboxylated Nor) equivalent to $5-90 \%$ Nor. Calculate concentration of Nor and Tnd from the corresponding regression equations. The same procedure was followed to determine both drugs in Conaz ${ }^{\circledR}$ tablets using aliquots from the test solution equivalent to $0.25-1 \mathrm{mg}$ Nor and $0.375-1.5 \mathrm{mg}$ of Nor and Tnd respectively.

TLC-Densitometric Method Construction of Calibration Curve for Nor and Tnd: Accurately measured aliquots equivalent to $0.4-2 \mathrm{mg}$ Nor and $2.4-10 \mathrm{mg}$ Tnd were transferred from stock solution 1 and 2 respectively into two separate series of 5-ml volumetric flasks. Complete to volume with methanol. Apply $10 \mu \mathrm{l}$ of each solution to HPTLC plates $(20 \times 20)$, spots are $2 \mathrm{~cm}$ apart from each other and $1.5 \mathrm{~cm}$ from the bottom edge of the plate. The plate is placed in a chromatographic tank previously saturated with the mobile phase isopropanol:butanol:concentrated ammonia: water $(25: 50: 5: 25, \mathrm{v} / \mathrm{v} / \mathrm{v} / \mathrm{v})$. Develop the plate by ascending chromatography and detect the spots under $254 \mathrm{~nm}$. Scan the spots at $280 \mathrm{~nm}$. A calibration graph for each drug was obtained by plotting area under the peak (AUP) against drug concentration.

Assay of Laboratory Prepared Mixtures and Conaz ${ }^{\mathbb{R}}$ Tablets: The procedure as under 'Construction of Calibration Curve for Nor and Tnd' was carried by mixing aliquots from stock solution 4 equivalent to $0.4-3.5 \mathrm{mg}$ Nor and $0.6-5.25 \mathrm{mg}$ Tnd, add aliquots from stock solution 3 (Nor degradation product) equivalent to $5-70 \%$ Nor. Calculate concentration of Nor and Tnd from the corresponding regression equations. The same procedure was followed to determine both drugs in Cona ${ }^{\circledR}$ tablets using aliquots equivalent to $0.4-1.8 \mathrm{mg}$ Nor and $2.4-3 \mathrm{mg}$ Tnd from test solution.

Second Derivative Ratio Spectra Method Construction of Calibration Curve: Aliquots of stock solution 1 equivalent to $0.01-0.07 \mathrm{mg}$ Nor were transferred into a series of $10-\mathrm{ml}$ volumetric flasks. The volume was completed with methanol. Absorption spectra were recorded and divided by the spectrum of Tnd $(10 \mu \mathrm{g} / \mathrm{ml})$. The resulting ratio spectra were stored and their $2 \mathrm{nd}$ derivative was computed at $\Delta \lambda=4 \mathrm{~nm}$ intervals and the scaling factor $=10$. The Amplitude of the signal at $282 \mathrm{~nm}$ was measured. The calibration curve was obtained by plotting mean amplitude against drug concentration.

Determination of Nor in Laboratory Prepared Mixtures and in Conaz ${ }^{\circledR}$ Tablets: The procedure as under 'Construction of Calibration Curve' was carried by mixing aliquots from stock solution 4 equivalent to $0.01-$ $0.07 \mathrm{mg}$ Nor and $0.015-0.105 \mathrm{mg}$ Tnd and aliquots equivalent to $5-50 \%$ Nor from stock solution 3 (Nor degradation product). Concentration of Nor was calculated from the corresponding regression equation. The same procedure was followed to determine Nor in $\mathrm{Conaz}^{\mathbb{B}}$ tablets using aliquots from test solution equivalent to $0.02-0.05 \mathrm{mg}$ of Nor.

\section{Results and Discussion}

The structures of Nor, Tnd and different known degradation products of Nor are shown in Fig. 1.

The minimum pharmacophore required for significant antibacterial activity of quinolones consists of the 4-pyridone ring with a 3-carboxylic group. ${ }^{41)}$ In other words, positions C-3, C-4 are the most structurally critical and substitution of other groups at these positions results in loss of activity. ${ }^{42)}$ For Nor, the antibacterial activity involves the breakdown of the double stranded DNA and hence cell death. This is achieved via strong binding of the drug to gyrase DNA complex in the presence of $\mathrm{Mg}^{2+}$, which acts as a bridge between the phosphate groups of DNA and the carbonyl and carboxylate moieties of Nor. ${ }^{43)}$ Moreover the piperazino group at the 7th position seems to achieve enhancing spectrum and in vivo activity. ${ }^{41,42)}$

Degradation of Nor Nor is a photosensitive drug. ${ }^{4,5,44)}$ The drug decomposes upon prolonged exposure to light, yielding three identified products, the amino, ethylenediamine and formyl piperazine derivatives. ${ }^{444)}$ These photodecomposition products are coherent to the piperazino group. On the other hand, Nor decomposes yielding 3-decarboxylated Nor on subjecting its neutral solution at $70^{\circ} \mathrm{C}$ to light and oxygen and also on prolonged heating of its solution in $2 \mathrm{~mol} / 1 \mathrm{HCl}$ at $100^{\circ} \mathrm{C}^{4,44)}$ This decarboxylated degradant has a particular importance due to its coherency to the 4-pyridone-3-carboxylic moiety (minimum pharmacophore required for significant antibacterial activity of quinolones. ${ }^{41,42)}$ Besides, the 3-decarboxylated Nor was identified as a precipitate in Nor injection ${ }^{39)}$ and as an impurity in Nor powder. ${ }^{40)}$ These reasons make the development of the proposed methods to be carried out in the presence of the 3-decarboxylated<smiles>[R2]c1cc2c(cc1F)c(=O)c([R])cn2CC</smiles>

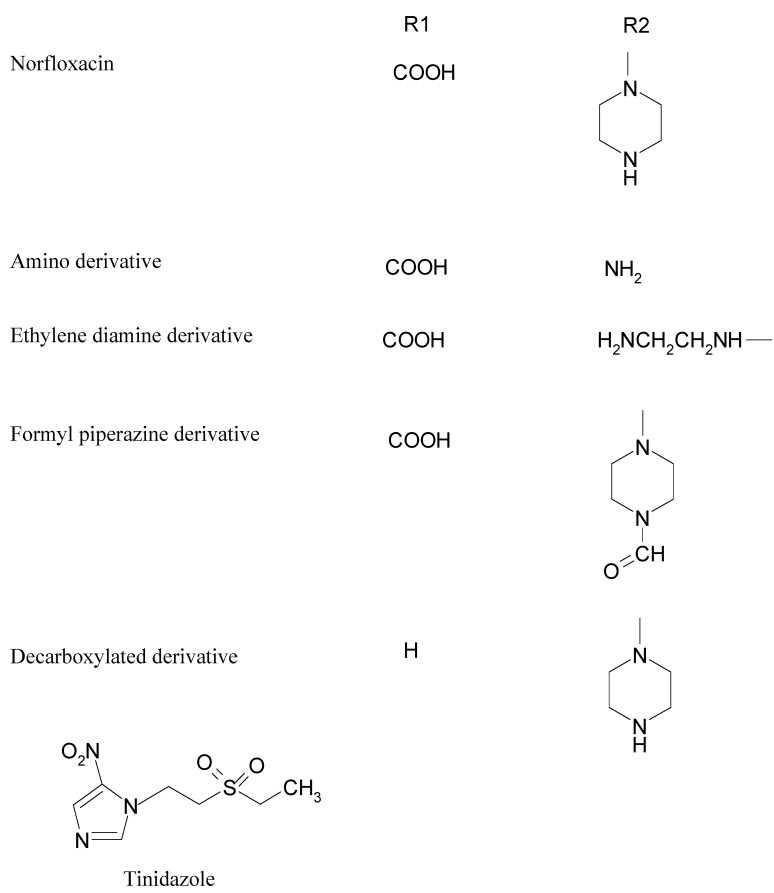

Fig. 1. Chemical Structures of Nor, Its Degradation Products and Tnd 


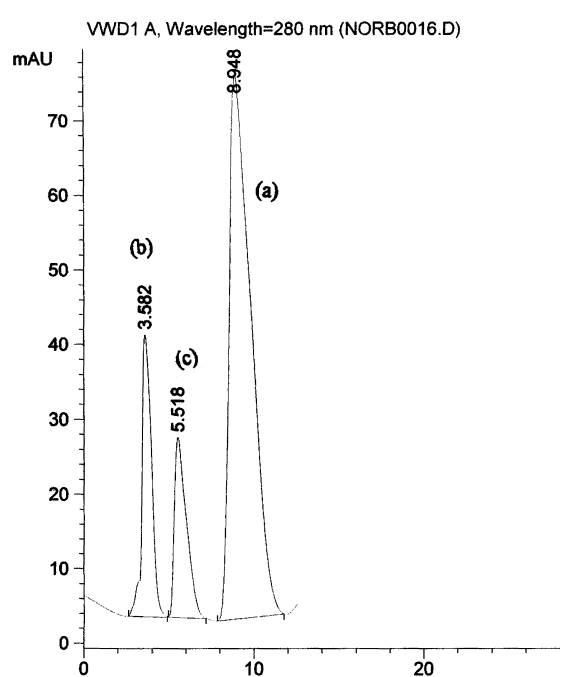

Fig. 2a. LC Chromatogram Showing a: Nor $(60 \mu \mathrm{g} / \mathrm{ml})$, b: Tnd $(90 \mu \mathrm{g} / \mathrm{ml})$ and c: Decarboxylated Nor (Equivalent to $50 \%$ Nor)

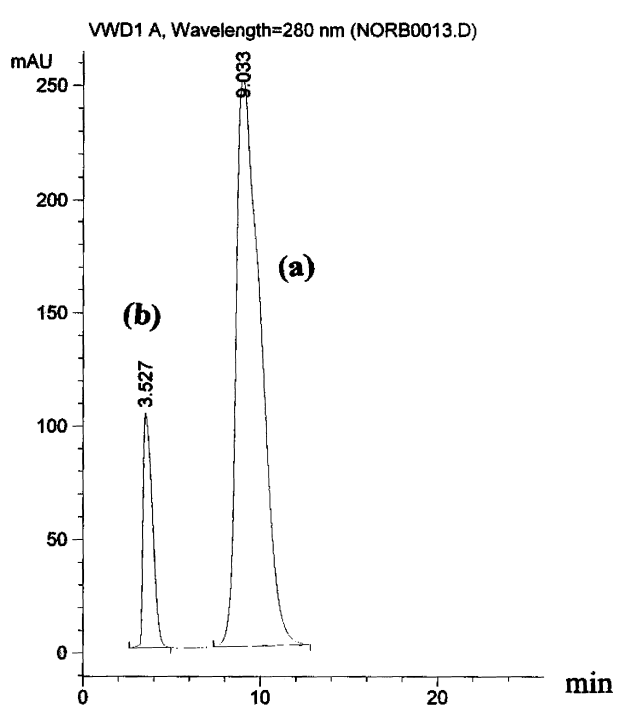

Fig. 2b. LC Chromatogram Showing a Commercial Sample a: Nor $(200 \mu \mathrm{g} / \mathrm{ml})$ and $\mathrm{b}$ : Tnd $(300 \mu \mathrm{g} / \mathrm{ml})$

degradation product of Nor a great need.

Method Development. LC Method The developed LC method has been applied for the simultaneous determination of Nor and Tnd in the presence of Nor decarboxylated degradant.

Various columns were tried such as hypersil BDS $5 \mu \mathrm{m}$ $(250 \times 4.6 \mathrm{~mm})$, Spherisorb ODS $5 \mu \mathrm{m}(250 \times 4.6 \mathrm{~mm})$ and $\mu$-Bondapack C18, $5 \mu \mathrm{m}(300 \times 4.6 \mathrm{~mm})$. The later was used as it showed minimum elution time, with good resolution and it was employed for method validation.

Several mobile phases were tried to accomplish complete separation of Nor, Tnd and the decarboxylated Nor. On using the mobile phase phosphate buffer $\mathrm{pH} 3.2:$ methanol $(3: 1$, $\mathrm{v} / \mathrm{v})$ good resolution and peak symmetry were obtained. The retention times were 8.9, 5.5 and 3.6 for Nor, decarboxylated Nor and Tnd, respectively (Figs. 2a, 2b)

The composition of the mobile phase was adjusted by varying the organic to aqueous ratio to give the best results. Meanwhile, increasing the proportion of methanol, results in incomplete separation of the three peaks. A further increase

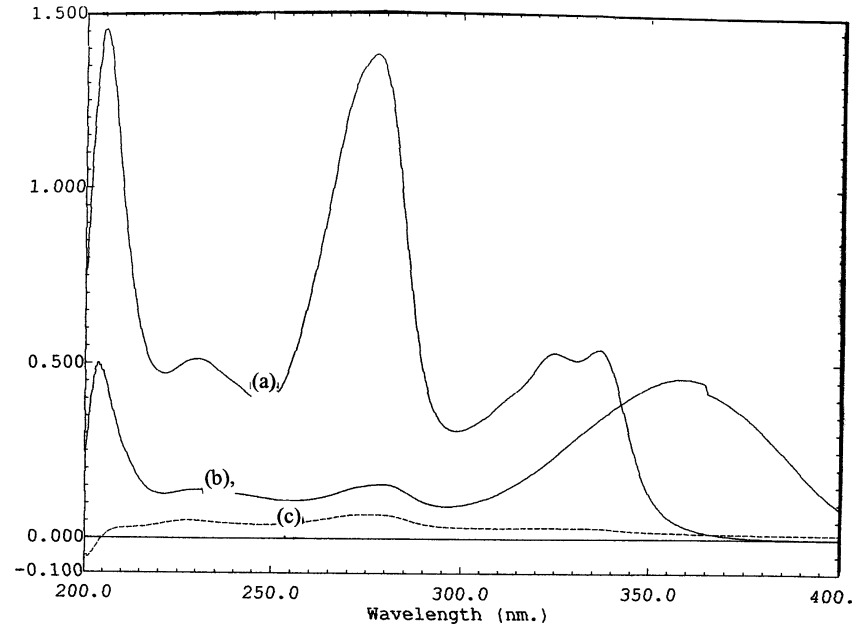

Fig. 3. Zero Order Spectra of a: Nor $(3 \mu \mathrm{g} / \mathrm{ml})$, b: Tnd $(10 \mu \mathrm{g} / \mathrm{ml})$ and c: Decarboxylated Nor $(10 \mu \mathrm{g} / \mathrm{ml})$

in the aqueous proportion results in prolonged retention times. The $\mathrm{pH} 3.2$ was chosen such that higher retention of Nor was achieved since its $\mathrm{p} K_{\mathrm{a}}$ is 6.4 and hence better separation between the three components was obtained. The ion pairing approach was used in order to reduce the tailing and improve the resolution. Pentane sulfonic acid sodium salt at $0.005 \mathrm{~m}$ concentration was selected to serve this purpose. The system suitability tests were used to verify that the resolution and reproducibility of the chromatographic system are adequate for analysis. ${ }^{45)}$

TLC-Densitometric Method Some commonly used stationary phases (such as kieselgel, silica gel and alumina) were tried. Silica gel provided the best compromise for fast rate of solvent migration, good resolution and regular spots.

Several mobile phases were tried to separate Nor, its decarboxylated degradate and Tnd from each other. Complete separation was carried out using the chosen mobile phase.

$R f$ for Nor $=0.3 . R f$ for Tnd $=0.8$ and $R f$ for decaboxylated Nor $=0.54$

Second Derivative Ratio Spectra Method The zero order spectra of Nor, Tnd and Nor decarboxylated degradant showed severe overlap (Fig. 3). Analysis of Nor in such mixture required the application of second derivative ratio spectrometry. It is necessary to test the influence of $\Delta \lambda$, the scaling factor and the divisor standard concentration. $\Delta \lambda=4$ and scaling factor $=10$ were selected as optimum values and best results were obtained on using Tnd standard $(10 \mu \mathrm{g} / \mathrm{ml})$ as divisor. Nor could be determined in the range $1-7 \mu \mathrm{g} / \mathrm{ml}$ by dividing the spectrum of Nor by that of Tnd $(10 \mu \mathrm{g} / \mathrm{ml})$ and the 2 nd derivative of the ratio spectrum was recorded. Nor measurements were carried out at $282 \mathrm{~nm}$ where there is a zero crossing between the 2 nd derivative of the ratio spectrum of Nor and the 2nd derivative of the ratio spectrum of Nor degradation product by Tnd $(10 \mu \mathrm{g} / \mathrm{ml})$ (Fig. 4). The spectrometric method can determine only Nor, since Tnd spectrum shows no zero crossing with both Nor and Tnd spectra (at $370 \mathrm{~nm}$ Nor and its degradation product shows some degree of interference especially at high concentrations, and the results for the determination of Tnd were not repeatable).

Method Validation. Linearity The linearity of the responses of the two drugs was verified at 6 concentration lev- 


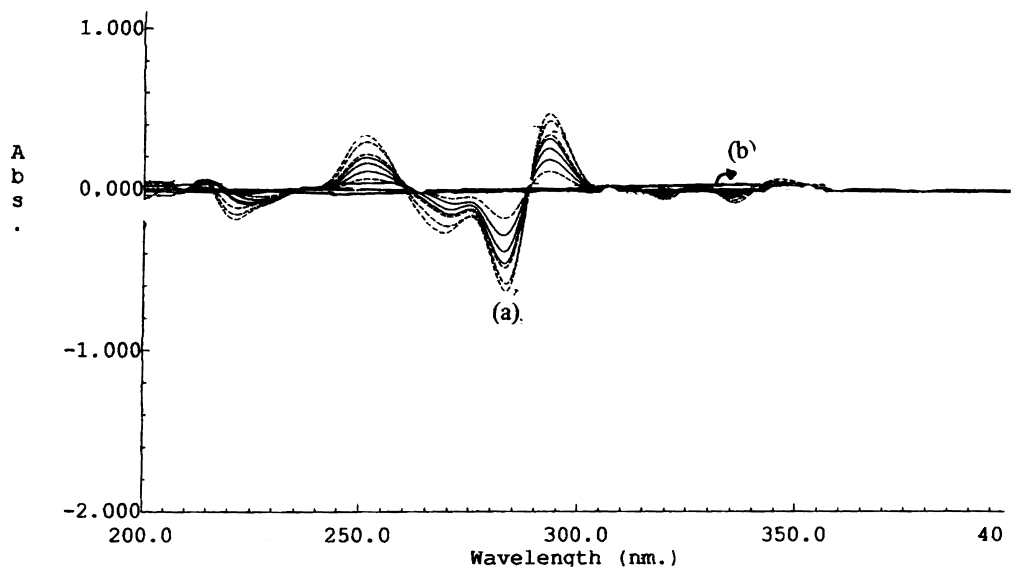

Fig. 4. Second Order Ratio Spectra of a: Nor $(1-7 \mu \mathrm{g} / \mathrm{ml})$, b: Decarboxylated Nor (Equivalent to $5-50 \%$ Nor)

The divisor is $10 \mu \mathrm{g} / \mathrm{ml}$ Tnd.

Table 1. The Conditions and the Results Obtained in the Determination of Nor and Tnd Using the Proposed Methods

\begin{tabular}{|c|c|c|c|c|c|}
\hline \multirow[b]{2}{*}{ Item } & \multicolumn{3}{|c|}{ Nor } & \multicolumn{2}{|c|}{ Tnd } \\
\hline & LC method & $\begin{array}{l}\text { TLC-densitometric } \\
\text { method }\end{array}$ & ${ }^{2} \mathrm{DD}_{282}$ method & LC method & $\begin{array}{l}\text { TLC-densitometric } \\
\text { method }\end{array}$ \\
\hline Linearity range & $20-225 \mu \mathrm{g} / \mathrm{ml}$ & $0.8-4 \mu \mathrm{g} /$ spot & $1-7 \mu \mathrm{g} / \mathrm{ml}$ & $37.5-375 \mu \mathrm{g} / \mathrm{ml}$ & $4.8-20 \mu \mathrm{g} / \mathrm{spot}$ \\
\hline Regression equation & $\mathrm{AUP}=130 \mathrm{C}+82$ & $\begin{array}{l}\mathrm{AUP}=3411 \times \mathrm{C} \\
\quad+431\end{array}$ & $\begin{array}{c}{ }^{2} \mathrm{DD}_{282}=0.0526 \mathrm{C} \\
+0.0067\end{array}$ & $\mathrm{AUP}=15 \mathrm{C}+15$ & $\mathrm{AUP}=242 \mathrm{C}+13$ \\
\hline Coefficient of determination & 0.999 & 0.997 & 0.997 & 0.999 & 0.998 \\
\hline $\mathrm{S}_{\mathrm{b}}$ & 2.5 & $1.11 \times 10^{2}$ & $6.1 \times 10^{-4}$ & 0.22 & 2.25 \\
\hline $\mathrm{S}_{\mathrm{a}}$ & $2.43 \times 10^{2}$ & $1.09 \times 10^{2}$ & $26.8 \times 10^{-4}$ & 2.52 & 26.62 \\
\hline LOQ & $0.06 \mu \mathrm{g} / \mathrm{ml}$ & $0.03 \mu \mathrm{g} / \mathrm{spot}$ & $0.015 \mu \mathrm{g} / \mathrm{ml}$ & $2 \mu \mathrm{g} / \mathrm{ml}$ & $0.3 \mu \mathrm{g} / \mathrm{spot}$ \\
\hline LOD & $0.02 \mu \mathrm{g} / \mathrm{ml}$ & $0.01 \mu \mathrm{g} / \mathrm{spot}$ & $0.005 \mu \mathrm{g} / \mathrm{ml}$ & $0.6 \mu \mathrm{g} / \mathrm{ml}$ & $0.1 \mu \mathrm{g} / \mathrm{spot}$ \\
\hline \multicolumn{6}{|l|}{ System suitability } \\
\hline 1. Selectivity factor & 2.47 & & & 2.47 & \\
\hline 2. Number of theoretical plates & 3000 & & & 2304 & \\
\hline 3. Resolution factor & 2.4 & & & 1.5 & \\
\hline 4. RSD & 1.45 & 0.85 & 0.64 & 0.93 & 0.85 \\
\hline \multicolumn{6}{|l|}{ Results } \\
\hline Drug in dosage form & $101.34 \pm 0.75$ & $105.25 \pm 1.33$ & $101.11 \pm 1.62$ & $92.99 \pm 1.36$ & $101.09 \pm 0.79$ \\
\hline Drug added & $99.72 \pm 1.25$ & $100.66 \pm 0.93$ & $99.22 \pm 0.62$ & $99.34 \pm 0.70$ & $100.88 \pm 0.44$ \\
\hline Drug in synthetic mixtures & $99.46 \pm 0.89$ & $99.59 \pm 1.38$ & $99.40 \pm 1.66$ & $99.54 \pm 1.14$ & $101.24 \pm 0.89$ \\
\hline
\end{tabular}

Batch 16929 was used for the determination of Nor (LC methods and ${ }^{2} \mathrm{DD}_{282}$ ) and Tnd (LC method) while batch 16932 was used for the determination of Nor and Tnd by TLC-densitomteric method. $\mathrm{S}_{\mathrm{a}}$ and $\mathrm{S}_{\mathrm{b}}$ are the standard error of the slope and intercept, respectively.

els ranging from $20-225 \mu \mathrm{g} / \mathrm{ml}, 0.8-4 \mu \mathrm{g} /$ spot and $1-$ $7 \mu \mathrm{g} / \mathrm{ml}$ for Nor by LC, TLC and ${ }^{2} \mathrm{DD}$ methods, respectively and ranging from $37.5-375 \mu \mathrm{g} / \mathrm{ml}$ and $4.8-20 \mu \mathrm{g} / \mathrm{spot}$ for Tnd by LC and TLC methods, respectively. The calibration curves were constructed by plotting either mean area under the peak (AUP) for the chromatographic methods or mean amplitude for ${ }^{2} \mathrm{DD}$ method against concentration $(C)$ of each drug. The regression equations $(Y=b C \pm a)$ and the RSD of slope and intercept are summarized in Table 1 . The linearity of calibration graphs and adherence to Beer's law were validated by the high value of coefficient of determination.

Accuracy and Precision Accuracy of the results was calculated by $\%$ recovery of pure samples of intact drug analyzed by the proposed methods (Table 2). The percentage recoveries of Nor and Tnd in laboratory prepared mixtures of both were determined (Table 1). One-way ANOVA was used to compare the results of the proposed and official methods, where it was concluded that there is no statistically significant difference between them. Inter-day and intra-day accu- racy and precision of the proposed methods were also determined (Tables 3a, 3b). The RSD of the assay results expressed as a percentage was used to evaluate the method precision.

Specificity Specificity is the ability of the analytical method to measure the analyte response in the presence of interferences (degradation products, related substances, excipients, etc.). Specificity was checked by adding the degradation product of Nor and the response of the analyte was determined by the proposed methods. In application of the proposed methods to pharmaceutical formulation no interference from the excipients appeared. Hence the proposed methods are capable of determining the drugs of interest selectively in their pharmaceutical formulation. Standard addition technique was also applied to assess accuracy of the proposed methods (Table 1).

Stability Analyzing commercial samples kept at room temperature on laboratory bench or in the refrigerator for six months showed no degradation products (degradation prod- 
Table 2. The Results of the Proposed and Official Methods in the Determination of Nor and Tnd in Bulk

\begin{tabular}{|c|c|c|c|c|c|c|c|}
\hline \multirow[b]{2}{*}{ Item Method } & \multicolumn{4}{|c|}{ Nor } & \multicolumn{3}{|c|}{ Tnd } \\
\hline & $\begin{array}{c}\mathrm{LC} \\
\% \text { recoveries }\end{array}$ & $\begin{array}{l}\text { TLC-densitometric } \\
\% \text { recoveries }\end{array}$ & $\begin{array}{l}{ }^{2} \mathrm{DD}_{282} \\
\text { \% recoveries }\end{array}$ & $\begin{array}{c}\text { Official }^{a)} \\
\% \text { recoveries }\end{array}$ & $\begin{array}{c}\mathrm{LC} \\
\% \text { recoveries }\end{array}$ & $\begin{array}{l}\text { TLC-densitometric } \\
\% \text { recoveries }\end{array}$ & $\begin{array}{l}\text { Official }^{a)} \\
\% \text { recoveries }\end{array}$ \\
\hline & 101.35 & 101.81 & 100.44 & 101.90 & 99.55 & 100.32 & 99.50 \\
\hline & 100.81 & 101.83 & 101.48 & 102.00 & 100.93 & 101.24 & 99.80 \\
\hline & 101.29 & 100.88 & 100.93 & 101.35 & 100.90 & 99.74 & 100.20 \\
\hline & 99.40 & 99.47 & 100.33 & 99.80 & 99.67 & 99.64 & 101.30 \\
\hline & 98.48 & 101.06 & 100.63 & 100.50 & 99.71 & 101.79 & 100.90 \\
\hline & 98.06 & 101.03 & 102.00 & 100.92 & 101.85 & 100.96 & 101.70 \\
\hline Mean & 99.90 & 101.01 & 100.97 & 101.08 & 100.44 & 100.62 & 100.57 \\
\hline$F(5.05)^{a)}$ & 2.92 & 1.03 & 1.71 & & 1.13 & 1.03 & \\
\hline$\left.t(2.23)^{a}\right)$ & 1.72 & 0.14 & 0.25 & & 0.25 & 0.10 & \\
\hline
\end{tabular}

Each result is the average of three experiments. a) Eur. Ph. 2005 non aqueous titrimetric method. One way ANOVA was carried out to compare the results of the proposed and reference methods. The calculated $F$ was found to be 1.91 and 0.067 for Nor and Tnd respectively. The tabulated $F$ was found to be 3.1 and 3.68 respectively, indicating no significant difference between the proposed and reference methods.

Table 3a. Intra-day and Inter-day Assay Variations for the Determination of Nor by the Proposed Methods

\begin{tabular}{|c|c|c|c|c|c|c|c|c|c|}
\hline & \multicolumn{3}{|c|}{$\mathrm{LC}$} & \multicolumn{3}{|c|}{ TLC-densitometric } & \multicolumn{3}{|c|}{ Second derivative ratio } \\
\hline \multicolumn{10}{|l|}{ Intra-day } \\
\hline $\begin{array}{c}0 \mathrm{~d} \\
\text { Mean of concentration } n=3\end{array}$ & 25.321 & 75.385 & 100.879 & 2.33 & 1.416 & 3.526 & 2.041 & 3.056 & 5.075 \\
\hline S.D. & 0.029 & 0.127 & 0.332 & 0.017 & 0.001 & 0.003 & 0.002 & 0.01 & 0.04 \\
\hline$\%$ RSD & 0.115 & 0.168 & 0.328 & 0.699 & 0.071 & 0.074 & 0.098 & 0.327 & 0.788 \\
\hline $1 \mathrm{~d}$ & & & & & & & & & \\
\hline Mean of concentration $n=3$ & 25.367 & 75.518 & 101.013 & 2.444 & 1.416 & 3.546 & 2.035 & 3.057 & 5.093 \\
\hline S.D. & 0.021 & 0.159 & 0.293 & 0.009 & 0.003 & 0.005 & 0.003 & 0.004 & 0.007 \\
\hline$\%$ RSD & 0.083 & 0.211 & 0.29 & 0.368 & 0.212 & 0.141 & 0.147 & 0.131 & 0.137 \\
\hline $2 \mathrm{~d}$ & & & & & & & & & \\
\hline Mean of concentration $n=3$ & 25.236 & 75.3 & 100.528 & 2.44 & 1.409 & 3.529 & 2.035 & 3.048 & 5.088 \\
\hline S.D. & 0.064 & 0.073 & 0.046 & 0.009 & 0.007 & 0.004 & 0.004 & 0.004 & 0.018 \\
\hline$\%$ RSD & 0.254 & 0.097 & 0.046 & 0.369 & 0.497 & 0.113 & 0.197 & 0.131 & 0.354 \\
\hline \multicolumn{10}{|l|}{ Inter-day } \\
\hline Mean of concentration $n=3$ & 25.308 & 75.401 & 100.807 & 2.439 & 1.414 & 3.534 & 2.037 & 3.054 & 5.085 \\
\hline S.D. & 0.067 & 0.11 & 0.251 & 0.006 & 0.004 & 0.011 & 0.004 & 0.005 & 0.009 \\
\hline$\%$ RSD & 0.265 & 0.146 & 0.249 & 0.246 & 0.283 & 0.311 & 0.196 & 0.164 & 0.177 \\
\hline
\end{tabular}

Concentration was measured in $(\mu \mathrm{g} / \mathrm{ml})$ for LC and spectrometric methods and in $(\mu \mathrm{g} / \mathrm{spot})$ for TLC-densitometric method.

Table 3b. Intra-day and Inter-day Assay Variations for the Determination of Tnd by the Proposed Methods

\begin{tabular}{|c|c|c|c|c|c|c|}
\hline & \multicolumn{3}{|c|}{$\mathrm{LC}$} & \multicolumn{3}{|c|}{ TLC-densitometric } \\
\hline \multicolumn{7}{|l|}{ Intra-day } \\
\hline $\begin{array}{c}0 \mathrm{~d} \\
\text { Mean of concentration } n=3(\mu \mathrm{g} / \mathrm{ml})\end{array}$ & & 2254 & 259 & 6062 & 7015 & 1000 \\
\hline $\begin{array}{c}\text { Mean or concentration } n=3(\mu \mathrm{g} / \mathrm{mI}) \\
\text { S.D. }\end{array}$ & $\begin{array}{r}3 / .44 \\
0.14\end{array}$ & 225.4 & 1.33 & 0.006 & .015 & $\begin{array}{r}10.290 \\
0.103\end{array}$ \\
\hline \%RSD & 0.374 & 1.192 & 0.514 & 1.01 & 0.527 & 0.193 \\
\hline \multicolumn{7}{|l|}{$1 \mathrm{~d}$} \\
\hline Mean of concentration $n=3$ & 37.09 & 225.93 & 259.15 & 6.047 & 7.007 & 16.25 \\
\hline S.D. & 0.214 & 1.075 & 0.751 & 0.045 & 0.017 & 0.235 \\
\hline$\%$ RSD & 0.577 & 0.476 & 0.29 & 0.44 & 0.238 & 1.446 \\
\hline \multicolumn{7}{|l|}{$2 \mathrm{~d}$} \\
\hline Mean of concentration $n=3$ & 37.11 & 225.29 & 258.423 & 6.072 & 7.037 & 16.262 \\
\hline S.D. & 0.43 & 1.212 & 1.506 & 0.37 & 0.043 & 0.207 \\
\hline$\% \mathrm{RSD}$ & 1.159 & 0.538 & 0.583 & 0.601 & 0.611 & 1.27 \\
\hline \multicolumn{7}{|l|}{ Inter-day } \\
\hline Mean of concentration $n=3$ & 37.213 & 225.54 & 258.858 & 6.06 & 7.02 & 16.269 \\
\hline S.D. & 0.197 & 0.342 & 0.384 & 0.013 & 0.016 & 0.024 \\
\hline$\%$ RSD & 0.053 & 0.152 & 0.148 & 0.215 & 0.228 & 0.148 \\
\hline
\end{tabular}

Concentration was measured in ( $\mu \mathrm{g} / \mathrm{ml})$ for LC method and in $(\mu \mathrm{g} / \mathrm{spot})$ for TLC-densitometric method. 
uct was found to be $<$ LOQ). Only under stressed conditions (heating in the presence of acid) degradation product appeared. The results were found as same as in laboratory prepared mixtures (Table 1).

Robustness The robustness of a method is its ability to remain unaffected by small change in parameters. In LC method, variation of $\mathrm{pH}$ of the mobile phase by \pm 0.1 did not have significant effect on the chromatographic resolution. In the proposed LC and TLC-densitometric methods, small changes in proportions of different components by $\pm 0.2 \%$ of the mobile phase did not affect the complete separation of the three components.

Limit of Detection and Limit of Quantification According to ICH recommendations ${ }^{46)}$ the approach based on $\mathrm{SD}$ of the response and the slope was used for determining the detection and quantitation limits (LOD and LOQ). The theoretical values were assessed practically and given in Table 2 .

\section{Conclusion}

Three stability-indicating methods are proposed for the determination of Nor as well as Tnd in binary mixture. The first method is LC and the second is TLC-densiotmetry. Both methods are selective, accurate and have the advantage of determining both drugs simultaneously and in presence of decarboxylated degradate of Nor. The third method is based on the use of derivative ratio zero crossing spectrophotometric technique which has the advantages of low cost, availability of equipments and sensitivity, but it can only determine Nor. The LC method is most reliable from the three methods and can determine both Nor and Tnd, while the spectrometric method is the most sensitive one. The results obtained by the proposed methods are statistically compared with those obtained by the official ones (non aqueous titrimetric methods for $\mathrm{Nor}^{3)}$ and $\mathrm{Tnd}^{24)}$ using one way ANOVA from which it is concluded that there is no significant difference between them. The suggested methods are successfully applied to the analysis of the cited drugs in laboratory prepared mixtures and in the pharmaceutical preparation. The validity of the proposed methods is further assessed by applying the standard addition technique.

\section{References}

1) Goldstein E. J., Am. J. Med., 82, 3-17 (1987).

2) Wolfson J. S., Hooper D. C., Ann. Intern. Med., 108, 238-251 (1988).

3) "European Pharmacopoeia," fifth ed., European Department for the Quality of Medicines, Council of Europe, Strasbourg, France, 2005, pp. $2118-2119$.

4) Nangia A., Lam F., Hung C. T., Drug Dev. Ind. Pharm., 17, 681-694 (1991).

5) Cordoba-Borrego M., Cordoba-Diaz M., Cordoba-Diaz D., J. Pharm. Biomed. Anal., 18, 919-926 (1999).

6) Cuiping C., Xingrong L., Rujin W., J. Pharm. Biomed. Anal., 11, $717-724$ (1993).

7) Hong J. W., Liu Y. W., Luo Y. Y., Fenxi Ceshi Xuebao, 18, 62-63 (1999).

8) Samanidou V. F., Christodoulou E. A., Papdoyannis I. N., J. Sep. Sci., 28, 555-565 (2005)

9) Zeng Z. L., Yang G. X., Chen Z. L., Huang X. H., J. Chromatogr. B, 821, 202-209 (2005).

10) Rao R. N., Nagaraju V., J. Pharm. Biomed. Anal., 34, 1049-1056 (2004).

11) Lim J. W., Park B. W., Yun H. I., J. Chromatogr., B: Anal.Technol. Bio- med. Life Sci., 772, 185-189 (2002)

12) Lin F., Lin M. D., Wu Y. X., Wang, F., Fenxi Ceshi Xuebao, 23, 4347 (2004)

13) Prat M. D., Benito J., Compano R., Hernandez-Arteseros J. A., Granados M., J. Chromatogr. A, 1041, 27-33 (2004).

14) Amin A. S., Mostafa M. E., Desouki H. A., Abdallah A., Quim. Anal., 20, 93-98 (2001).

15) El-Khateeb S. Z., Abdel Razek S. A., Amer M. M., J. Pharm. Biomed. Anal., 17, 829-840 (1998).

16) Avadhanulu A. B., Mohan Y. R. R., Srinivas J. S., Anjaneyulu Y., Indian Drugs, 36, 296-300 (1999).

17) Han Y., Wu X., Yang J., Sun S., J. Pharm. Biomed. Anal., 38, 528531 (2005)

18) Du L. M., Yao H. Y., Fu M., Spectrochimica Acta part A, 61, 281286 (2005).

19) El-Kommos M. E., Saleh G. A., El-Gizawi S. M., Abou-Elwafa M. A., Talanta, 60, 1033-1050 (2003).

20) Morales-Munoz S., Luque-Garcia J. L., Luque de Castro M. D., J. Chromatogr. A, 1059, 25-31 (2004).

21) Ghoneim M. M., Radi A., Beltagi A. M., J. Pharm. Biomed. Anal., 25, 205-210 (2001).

22) Anagnostopoulos G. K., Kostopoulus P., Margantinis G., Tsiakos S. Arvanitidis D., J. Gastroenterology, 36, 325-328 (2003).

23) Mank T. G., Zaat J., Expert Opinion Investigational Drugs, 10, 1513 1519 (2001).

24) "European Pharmacopoeia," fifth ed., European Department for the Quality of Medicines, Council of Europe, Strasbourg, France, 2004, pp. $2585-2586$.

25) Liu J. H., Liu J. X., Li D. M., You G. P., Yaowu Fenxi Zazhi, 20, 329331 (2000).

26) Argekar A. P., Power S. G., Indian Drugs, 36, 399-402 (1999).

27) Bakshi M., Singh S., J. Pharm. Biomed. Anal., 34, 11-18 (2004).

28) Nagaraja P., Sunitha K. R., Vasantha R. A., Yanthirajan, H. S., J. Pharm. Biomed. Anal., 28, 527-535 (2002).

29) Feng W. Y., Cai S., Li S., Zhongguo Yiyao Gongye Zazhi, 33, 94-95 (2002).

30) Argekar A. P., Kapadia S. U., Raj S. V., Anal. Lett., 29, 1539-1549 (1996).

31) Ghosh S. K., Banerjie M., Indian Drugs, 33, 127-129 (1996).

32) Argekar A. P., Kapadia S. U., Raj S. V., J. Planar. Chromatogr. Mod. TLC, 9, 208-211 (1996).

33) Zarapkar S. S., Kanyawar N. S., Indian Drugs, 36, 293 -295 (1999).

34) More H. N., Mahadik K. R., Kadam S. S., Indian Drugs, 36, 144-146 (1999).

35) Prasad C. V. N., Parihar C., Sunil K., Parimoo P., Pharm. Sci., 33, 337-341 (1997).

36) Ramesh G., Singhai A. K., Agrawal R. K., Indian Drugs, 37, 348 349 (2000).

37) Srinivara-Reddy G. K., Bhatia M. S., Jain D. K., Trivedi P., Indian Drugs, 34, 190-193 (1997).

38) Razak O. A., El-Yazby F. A., Belal S. F., Abdel Gawad D. A., Bull. Fac. Pharm. Cairo Univ., 42, 371-383 (2004).

39) Li Y., Don S., Zhu Y., Yang J., Vang L., Zhongguo Yaoke Daxue Xuebao, 24, 33 (1993).

40) Guo H., Sun L., Zhang Z., Zhongguo Yiyao Gongye Zazhi, 20, 339 (1989).

41) Abraham D. J. (ed.), "Burger's Medicinal Chemistry and Drug Discovery," Vol. 5, sixth ed., John Wiley and Sons, Inc., Hoboken, New Jersey, 2003, pp. 584-585.

42) Actor P., Chow A. W., Dutko F. J., Mckinlay M. A., "Pharmaceuticals," Vol. 3, ed. by McGuire, Wiley-VCH, Weinheim, Germany, 2000, p. 1116.

43) Chen Z. F., Xiong R. G., Zuo J. L., Guo Z., You X. Z., Fun H. K., J. Chem. Soc., Dalton Trans., 2000, 4013 -4014 (2000).

44) Mazuel C., "Analytical Profile of Drug Substances," Vol. 20, ed. by Florey K., Academic Press, New York, 1999, pp. 557-600.

45) United States Pharmacopoeia 29 and National Formulary 24 US Pharmacopoeial Convention, Rockville, MD, 2006, pp. 2647-2649.

46) International Conference on Harmonization Draft Guideline on Validation Procedures: Definitions and Terminology, Vol. 60, Federal Register, 1999, p. 11260. 